\title{
An examination of the influence of eating location on the diets of Irish children
}

\author{
SJ Burke ${ }^{1, *}$, SN McCarthy ${ }^{1}$, JL O’Neill ${ }^{1}$, EM Hannon ${ }^{2}$, M Kiely $^{2}$, A Flynn $^{2}$ and M Gibney ${ }^{1}$ \\ ${ }^{1}$ Room 302, Human Nutrition Unit, School of Agriculture, Food Science and Veterinary Medicine, University College \\ Dublin, Belfield, Dublin 4, Ireland: ${ }^{2}$ Department of Food and Nutritional Sciences, University College Cork, Ireland
}

Submitted 30 November 2005: Accepted 23 May 2006: First published online 5 March 2007

\begin{abstract}
Objectives: To examine the influence of eating location on the quality of the diets of Irish children and to compare intakes at home with intakes at other people's homes and intakes outside the home, and to compare intakes at various locations outside the home.

Design: Food intake was measured using a 7-day weighed diary in 594 children from the Republic of Ireland (aged 5-12 years). Details of where the food was prepared or obtained were also recorded.

Results: Eighty-nine per cent of all eating occasions occurred at home; $<6 \%$ occurred at both other people's homes and outside the home (takeaway, restaurant, shop, other). The percentage of food energy from fat was above the recommended $35 \%$ at other people's homes and outside the home, specifically at takeaways and restaurants. Fibre and micronutrient intakes (per 10 MJ) were significantly higher at home than at the other locations $(P<0.05)$. Within the 'out' locations, fibre and micronutrient intakes were generally higher at restaurants and lower at shops. High consumers of foods outside the home had a statistically significant, but relatively small decline in nutrient intakes compared with non- or low consumers. Chips and processed potatoes, meat products, savouries, sugars and confectionery, and savoury snacks made the greatest contribution to foods consumed outside the home. Conclusions: The main focus of nutrition policies to improve the diets of Irish children should be the home environment rather than the food service sector. However, guidelines could call for better food choices outside the home to improve nutrient intakes.
\end{abstract}

\section{Keywords \\ Eating location \\ Food service sector \\ Ireland \\ Children}

The food service industry has become increasingly important in today's society. Euromonitor $(2004)^{1}$ found that between 1999 and 2003, the global number of food service outlets grew at a rate of $4 \%$ per annum to an estimated 11.2 million units. This increase has also occurred in Ireland, with the number of outlets increasing from 12541 to 13644 in the same time period, an increase of $8.8 \%$. The Annual Services Inquiry published by the Central Statistics Office has also demonstrated this increase. Between 2001 and 2002, the number of food service units increased from 10500 to $11775^{2}$. Correspondingly, the amount of money spent on the food service sector is also increasing. An 8\% increase on expenditure in the food service sector worldwide was reported from 1999 to $2002^{1}$. In Ireland, the household budget survey estimated the average weekly household expenditure on foods consumed away from home to be $€ 14.01$ in $1994 / 95^{3}$, and this increased to $€ 22.35$ in 1999/ 2000 , which accounted for $19 \%$ of food expenditure ${ }^{4}$.

The role of the food service sector on the diet has been examined to a small extent and in general has been found to be associated with higher fat intakes and poorer dietary habits in adults ${ }^{5-10}$. Foods eaten outside the home contributed to $24 \%$ of energy intakes in Irish adults ${ }^{11}$ and were also found to make a substantial contribution to fat intakes in the Irish population ${ }^{12}$.

There has been even less research into the role of the food service sector with regard to the diets of children. The literature is mainly from the USA, along with Canada and Australia. These studies suggest that consumption of foods from outside the home has an adverse effect on diet quality and may lead to increases in body mass index (BMI $)^{13-16}$. To date, there have been no published data examining the role of the food service sector with regard to children in Ireland but, given the expansion of the food service sector, a study in this area is clearly warranted for sensitive public health nutrition programmes aimed at children.

The National Children's Food Survey (NCFS) is a national food consumption survey which was carried out on Irish children, which also included information on the location of every food and drink item consumed over a 7 -day period ${ }^{17}$. This allows, for the first time, an examination of the influence of location on the diets of Irish children. The aim of the present study is to assess the 
number of eating occasions and compare nutrient intakes across the locations: home, other people's homes and outside the home, and across various locations outside the home. In addition, this study aims to determine the types of food consumed at various locations outside the home and to examine the diet quality across quantiles of eating outside the home. The implications of the findings in relation to the development of food-based dietary guidelines (FBDGs) will also be discussed.

\section{Methods}

\section{Survey sample and data collection}

The NCFS was a cross-sectional study of food and nutrient intakes of a representative sample of 594 Irish children aged 5-12 years. A 7-day weighed food record was used to measure food and beverage intakes. Respondents (children and/or their parents/guardians) recorded the day, time, location and meal type for each eating occasion, along with a detailed description of the food, the weight of the food and cooking method. Details of leftovers and recipes used were also requested. The foods were coded using McCance and Widdowson's The Composition of Foods $^{18,19}$ and published supplements ${ }^{20-28}$. Nutrient intakes were calculated using WISP ${ }^{\circledR}$ (Weighed Intake Software Program; Tinuviel Software). New food codes were generated for new foods on the market, generic Irish foods, supplements and for recipes. McCance and Widdowson's The Composition of Foods contains some food codes which relate to foods consumed outside the home, mainly takeaway foods such as burgers. These codes were augmented with new food codes pertaining to foods consumed from major retailers in the fast food industry where possible. However, some foods such as sandwiches and scones were considered to have the same nutritional composition regardless of whether they were consumed at home or outside the home. A series of questionnaires was used to collect additional information on health and lifestyle and the physical activity of the respondent and his/her parents. Questions on the frequency of consumption at food service sector establishments were also included in the questionnaires. Anthropometric measurements (weight, height, waist circumference, hip circumference and leg length) were taken for both the respondent and his/her parents. Further information on the methodology used for the NCFS, basic population characteristics and main findings can be found at www.iuna.net ${ }^{17}$.

\section{Locations}

In the present study, eating location refers to where the food was prepared or obtained rather than where the food was consumed. For example, foods purchased in a takeaway and eaten at home were coded as takeaway, whereas lunch prepared at home and brought to/con- sumed in school was coded as home. In the case where food was obtained from more than one location, location was coded as the one that provided the most food. Fourteen different location categories were used when coding the food diaries: (1) at home; (2) at a friend's home; (3) at a relative's home; (4) at a restaurant/hotel; (5) at a coffee shop/sandwich bar/delicatessen; (6) at a takeaway (non-ethnic); (7) bought in a shop; (8) at the child minder's; (9) at a public house or bar; (10) at an ethnic takeaway; (11) at the cinema; (12) at a social function; (13) at school; and (14) at a fast food chain. For the present study, these locations were aggregated to: (1) at home (respondent's own home); (2) at other people's homes (friend's home, at a relative's home and at the child minder's); and (3) outside the home (all other locations outside the home). For the foods consumed outside the home, this category was further divided into: (1) takeaway (at a takeaway (non-ethnic)/at an ethnic takeaway/at a fast food chain); (2) restaurant (at a restaurant/hotel/public house or bar); (3) from a shop; and (4) other locations outside the home (at a coffee shop/sandwich bar/delicatessen/at the cinema/at a social function/at school). Food is generally not provided in primary schools in Ireland, so school makes a very small contribution to food and nutrient intakes. For this reason, school has been included in the category 'other locations'. Shop-bought generally refers to when the respondent purchased and consumed food from a local shop. It does not include weekly shopping purchased for home use.

\section{Data analysis}

Data analysis was carried out using SPSS ${ }^{\circledR}$ version 10.0 (SPSS Inc.). Many different methods for calculating mean values were considered, for example means for the total population or for consumers only at a given location, or mean daily intakes over 7 days, or the number of days for which a food was consumed. For the present study, data analysis was carried out for those who were consumers of food at a given location, except where stated. Mean values were calculated as means per day over a total of 7 days, except for the number of eating occasions which was calculated as the mean number of eating occasions per week. Means and standard deviations were calculated across different locations for eating occasions over the week and the percentage contribution of each location to mean daily energy and nutrient intakes (as percentage energy from macronutrients, fibre and micronutrient intakes per $10 \mathrm{MJ}$ ). The association between sociodemographic and other health parameters (e.g. sex, age, social class, education level, location of residence, BMI and physical activity level) with regard to the number of eating occasions and the contribution of location to energy intakes was also examined.

Food intakes at each location outside the home were assessed in several ways. First, the percentage of consumers of each food group was determined. Then, the mean daily food group intakes (g) were calculated, 
along with the mean intake of each food group (g) per eating occasion. Finally, the percentage contribution of the food group to energy at each location was examined. Total mean daily nutrient intakes (at all locations) were analysed according to frequency of eating outside the home. Nutrient intakes of non-consumers of foods outside the home were compared with nutrient intakes of high, medium and low consumers of foods consumed outside the home. Different tertile groups were categorised, first based on frequency of eating outside the home and secondly based on the percentage contribution of foods consumed outside the home to energy intakes.

The percentage of respondents who consumed food at locations outside the home (from the food consumption database) were compared with the percentage of children who responded to the question of how often they ate at each location in the health and lifestyle questionnaire. These latter responses were aggregated to (1) less than once a fortnight or less frequently and (2) more than once a fortnight or more frequently.

\section{Statistical analysis}

One-way analysis of variance was used to examine whether significant differences existed between locations, and across the variables: social class, education level, physical activity level and BMI. Where significant differences existed, homogeneity of variance was examined using Levene's test. For values that satisfied Levene's test, the Scheffe post hoc test was used to determine which means differed. The Tahmane post hoc test was used for values that did not satisfy the Levene's test. Independent $t$-tests were used to determine significant differences between sex, age and location of residence across each of the locations. Independent $t$-tests were also used to determine whether or not differences in food intake at home compared with food intake outside the home were statistically significant. Pearson's $\chi^{2}$ was used to determine whether or not there was a relationship between sociodemographic and health-related variables and being a non-, low, medium or high consumer of foods from outside the home. Initial examination did not reveal differences between the sexes; therefore, results have been presented for boys and girls together. Values of $P<0.05$ were taken as significantly different.

\section{Results}

Table 1 shows the percentage of consumers, mean number of eating occasions per week and the percentage contribution to energy from foods consumed at home, other people's homes and outside the home. The results are also given for locations outside the home: at takeaways, at restaurants, at shops and at other locations. All respondents consumed foods at home, with 58 and $77 \%$ of the population having at least one eating occasion at other people's homes and outside the home, respectively, over the course of the survey week. For the average of 35 eating occasions per week, only 2.5 of these were consumed outside the home. In terms of the percentage of all eating occasions over the week, almost $90 \%$ occurred at home, with $<6 \%$ taking place at other people's homes and outside the home. The percentage contribution of foods to energy at each location showed similar patterns, with only $9 \%$ coming from foods outside the home. When this was further examined for consumers at each location, only $11 \%$ of energy was consumed outside the home. Regarding specific locations outside the home, the highest percentage of consumers was at takeaways (48\%), followed by shops (31\%) and restaurants (26\%). Outside the home, takeaways made the greatest contribution to energy at $4 \%$, with the other locations each contributing to $<2 \%$. When this was examined for consumers only at each location, 7-8\% of energy was consumed at takeaways/restaurants, with $5-6 \%$ consumed at shops and other locations. No particular patterns were observed across different sociodemographic groups for eating at various locations, except for differences across age groups. Older children had significantly more eating occasions and higher energy intakes outside the home than younger children $(P<0.05)$, particularly in takeaways and shops

Table 1 Percentage of consumers, mean number of eating occasions per week (and SD), percentage of eating occasions and the percentage contribution to energy at all locations for Irish children aged 5-12 years

\begin{tabular}{|c|c|c|c|c|c|c|c|c|}
\hline & \multirow[b]{2}{*}{$n$} & \multirow[b]{2}{*}{$\%$ consumers } & \multirow[b]{2}{*}{ Mean } & \multirow[b]{2}{*}{ (SD) } & \multirow{2}{*}{$\begin{array}{l}\% \text { of eating } \\
\text { occasions }\end{array}$} & \multirow{2}{*}{$\begin{array}{l}\text { \% of eating } \\
\text { occasions } \\
\text { outside } \\
\text { the home }\end{array}$} & \multicolumn{2}{|c|}{$\begin{array}{l}\% \text { contribution } \\
\text { to energy }\end{array}$} \\
\hline & & & & & & & Total population & Consumers only \\
\hline At home & 594 & 100.0 & 29.6 & $(7.0)$ & 89.0 & - & 85.1 & 85.1 \\
\hline At other people's homes & 349 & 58.8 & 3.1 & $(2.7)$ & 5.4 & - & 6.3 & 10.7 \\
\hline Outside the home & 459 & 77.3 & 2.5 & $(1.8)$ & 5.8 & - & 8.6 & 11.2 \\
\hline Takeaway & 288 & 48.5 & 1.4 & $(0.7)$ & 2.0 & 35.2 & 4.0 & 8.2 \\
\hline Restaurant & 157 & 26.4 & 1.3 & $(0.6)$ & 1.0 & 17.4 & 1.9 & 7.2 \\
\hline Shop & 182 & 30.6 & 1.9 & $(1.3)$ & 1.7 & 29.7 & 1.4 & 4.7 \\
\hline Other locations & 136 & 22.9 & 1.5 & $(1.2)$ & 1.0 & 17.7 & 1.3 & 5.7 \\
\hline
\end{tabular}

SD - standard deviation. 
$(P<0.01)$ (percentage contribution to energy only) (data not shown).

The mean percentage energy from macronutrients and intakes of fibre and selected micronutrients (per $10 \mathrm{MJ}$ ) at each location are presented in Table 2. The intakes of a wide range of nutrients were analysed, but only intakes of fibre, calcium, iron, folate and vitamin $\mathrm{C}$ are shown here. The percentage energy from protein decreased significantly, while the percentage energy from fat increased significantly, from foods consumed at home, to other people's homes to outside the home. Outside the home, the percentage of energy from fat was above the recommended $35 \%{ }^{29}$, while the percentage energy from carbohydrate was below the recommended $50 \%{ }^{29}$ at takeaways and restaurants. Foods consumed from a shop and other locations complied with the fat and carbohydrate recommendations, but the percentage of energy from sugar was significantly higher at these locations than at takeaways and restaurants. Intakes of all micronutrients examined were highest at home, followed by other people's homes, and lowest outside the home. In the case of some nutrients (e.g. calcium, iron, thiamin, riboflavin, vitamin $B_{12}$, folate and vitamin $C$ ), intakes at home were twice as high as intakes from outside the home. Comparing intakes across locations outside the home does not reveal a very clear pattern. However, overall, the highest micronutrient intakes were consumed in a restaurant whereas the lowest micronutrient intakes occurred in a shop.

Food intake was analysed, first for home and outside the home, and then for each location outside the home, and is presented as the percentage of consumers of each food group, the percentage contribution of food to energy and the grams of food per eating occasion, in Tables 3 and 4 , respectively. The percentage of consumers of all food groups was higher at home than outside the home. The percentage contribution of food groups to energy was also higher at home than outside the home for all food groups except poultry and game. Of the 16 food groups analysed, only the intake of poultry and game and meat products was found to be higher outside the home than at home. The foods consumed at takeaways and restaurants which were most important in terms of the number of consumers and/or the contribution to energy were: chips and processed potatoes; meat products; soups, sauces and miscellaneous foods; beverages; savouries; whole milk; and poultry and poultry dishes. The most important foods consumed at shops and other locations outside the home were: cakes, pastries and buns; sugars and confectionery; savoury snacks; beverages; creams, ice creams and desserts; chips and processed potatoes; meat products; savouries; and whole milk.

Total nutrient intakes (from all locations) were analysed according to quantiles of the percentage of energy consumed outside the home. The percentage of energy from macronutrients and fibre and selected micronutrient intakes per $10 \mathrm{MJ}$ for non-consumers of foods outside the home were compared with consumers of foods outside the home with low $(<6.5 \%)$, medium $(6.5-12.1 \%)$ and high $(>12.1 \%)$ percentage energy from foods consumed outside the home (Table 5). Intakes of fat were higher, whereas intakes of protein, carbohydrate, fibre and micronutrients were lower, in high consumers of foods from outside the home than low consumers (statistically significant in $60 \%$ of cases). In general, the intake of micronutrients decreased with increasing frequency of consumption of foods outside the home. Nutrient intakes were also examined by tertiles of eating occasions outside the home, and the findings were consistent with those described for tertiles of percentage energy.

Table 2 Intakes of macronutrients (as a percentage of energy), fibre and selected micronutrients (per 10 MJ) at home, at other people's homes and outside the home, and at various locations outside the home for Irish children aged 5-12 years

\begin{tabular}{|c|c|c|c|c|c|c|c|c|c|c|c|c|c|c|}
\hline & & & & & & & \multicolumn{8}{|c|}{ Outside the home } \\
\hline & \multicolumn{2}{|c|}{$\begin{array}{c}\text { Home } \\
(n=594)\end{array}$} & \multicolumn{2}{|c|}{$\begin{array}{l}\text { Other homes } \\
\quad(n=348)\end{array}$} & \multicolumn{2}{|c|}{$\begin{array}{c}\text { Outside the } \\
\text { home }(n=458)\end{array}$} & \multicolumn{2}{|c|}{$\begin{array}{l}\text { Takeaway } \\
(n=288)\end{array}$} & \multicolumn{2}{|c|}{$\begin{array}{l}\text { Restaurant } \\
(n=157)\end{array}$} & \multicolumn{2}{|c|}{$\begin{array}{c}\text { Shop } \\
(n=182)\end{array}$} & \multicolumn{2}{|c|}{$\begin{array}{c}\text { Other } \\
(n=134)\end{array}$} \\
\hline & Mean & $(\mathrm{SD})$ & Mean & $(\mathrm{SD})$ & Mean & (SD) & Mean & (SD) & Mean & (SD) & Mean & (SD) & Mean & (SD) \\
\hline \multicolumn{15}{|l|}{$\%$ Energy from } \\
\hline Protein & $13.8^{x}$ & (2.3) & $12.9^{y}$ & (6.8) & $10.9^{z}$ & (5.3) & $12.9^{\mathrm{a}}$ & (5.1) & $13.3^{\mathrm{a}}$ & (6.6) & $5.5^{\mathrm{b}}$ & $(4.0)$ & $7.9^{\mathrm{c}}$ & (5.2) \\
\hline Fat & $33.4^{x}$ & (4.6) & $35.4^{y}$ & (10.6) & $36.9^{z}$ & (10.3) & $38.6^{\mathrm{a}}$ & (7.4) & $37.8^{\mathrm{ab}}$ & (9.2) & $34.5^{\mathrm{bc}}$ & (16.2) & $33.5^{\mathrm{c}}$ & (13.4) \\
\hline Carbohydrate & 52.3 & (5.2) & 51.3 & (12.6) & $51.2^{\text {ns }}$ & (12.3) & $47.7^{\mathrm{a}}$ & (9.4) & $48.4^{a}$ & (11.1) & $58.4^{\mathrm{b}}$ & (17.4) & $57.2^{\mathrm{b}}$ & (15.9) \\
\hline Sugars & 24.0 & (5.6) & 24.2 & (15.0) & $25.6^{\text {ns }}$ & (16.2) & $17.5^{\mathrm{a}}$ & (10.8) & $22.2^{\mathrm{b}}$ & (14.3) & $41.8^{c}$ & (21.1) & $35.6^{d}$ & (19.6) \\
\hline \multicolumn{15}{|l|}{ Intake per $10 \mathrm{MJ}$} \\
\hline Fibre $(\mathrm{g})$ & $13.7^{x}$ & (3.8) & $13.1^{x}$ & (10.1) & $10.0^{y}$ & (6.3) & $10.4^{\mathrm{a}}$ & (5.5) & $12.5^{\mathrm{b}}$ & (7.9) & $6.5^{\mathrm{c}}$ & $(6.8)$ & $10.8^{\mathrm{ab}}$ & (9.5) \\
\hline Calcium (mg) & $1335.5^{x}$ & (361.4) & $908.6^{y}$ & $(567.7)$ & $602.1^{z}$ & $(462.1)$ & 563.2 & (445.5) & 631.9 & (485.2) & 629.8 & $(508.6)$ & $690.7^{\text {ns }}$ & (989.8) \\
\hline Iron (mg) & $14.2^{\mathrm{x}}$ & $(4.6)$ & $11.1^{y}$ & $(11.6)$ & $7.4^{z}$ & $(4.1)$ & 8.1 & (3.9) & 8.7 & $(4.2)$ & 5.7 & $(6.0)$ & $7.6^{\mathrm{ns}}$ & $(24.3)$ \\
\hline Folate $(\mu \mathrm{g})$ & $355.4^{x}$ & (149.6) & $236.3^{y}$ & (203.2) & $164.4^{z}$ & (90.6) & $193.4^{a}$ & (82.3) & $199.1^{a}$ & (111.2) & $101.4^{\mathrm{b}}$ & (131.4) & $120.5^{b}$ & (101.3) \\
\hline Vitamin C (mg) & $141.1^{x}$ & (107.4) & $97.0^{y}$ & (208.5) & $62.4^{z}$ & (96.9) & 47.1 & (57.2) & 72.5 & (113.1) & 85.0 & (257.1) & $80.9^{\text {ns }}$ & (156.2) \\
\hline
\end{tabular}

SD - standard deviation.

${ }_{x y z}$ Different superscripts are significantly different $(P<0.05)$ between locations: home, other people's homes and outside the home.

abcd Different superscripts are significantly different $(P<0.05)$ between locations outside the home: takeaway, restaurant, shop, other locations

${ }^{\text {ns }}$ No significant differences $(P \geq 0.05)$ across a given row. 
Table 3 Number and percentage of consumers for food groups consumed at home and outside the home, mean percentage contribution of food groups consumed at home and outside the home to total energy, and mean food group intakes (g) per eating occasion for Irish children aged $5-12$ years

\begin{tabular}{|c|c|c|c|c|c|c|c|c|c|c|c|c|}
\hline & \multicolumn{6}{|c|}{ Home } & \multicolumn{6}{|c|}{ Out } \\
\hline & \multirow[b]{2}{*}{$n$} & \multirow[b]{2}{*}{$\%$ consumers } & \multicolumn{2}{|c|}{$\begin{array}{l}\% \text { contri- } \\
\text { bution } \\
\text { to energy }\end{array}$} & \multicolumn{2}{|c|}{$\begin{array}{l}\text { g per eating } \\
\text { occasion }\end{array}$} & \multirow[b]{2}{*}{$n$} & \multirow[b]{2}{*}{$\%$ consumers } & \multicolumn{2}{|c|}{$\begin{array}{l}\% \text { contri- } \\
\text { bution } \\
\text { to energy }\end{array}$} & \multicolumn{2}{|c|}{$\begin{array}{l}\text { g per eating } \\
\text { occasion }\end{array}$} \\
\hline & & & Mean & (SD) & Mean & (SD) & & & Mean & (SD) & Mean & (SD) \\
\hline Savouries & 383 & 64.5 & 4.4 & (3.6) & 171.6 & (139.0) & 93 & 15.7 & $3.2^{\star \star}$ & $(2.7)$ & $156.9^{\text {ns }}$ & (124.0) \\
\hline Bread and rolls & 591 & 99.5 & 11.2 & (5.1) & 150.6 & (122.5) & 98 & 16.5 & $1.9^{\star \star \star}$ & (1.8) & 72.7††† & $(82.1)$ \\
\hline Cakes, pastries and buns & 547 & 92.1 & 6.2 & (4.3) & 63.1 & $(54.3)$ & 100 & 16.8 & $1.6^{\star \star *}$ & (1.2) & $45.2+\dagger \dagger$ & $(40.1)$ \\
\hline Whole milk & 536 & 90.2 & 10.2 & (6.3) & 509.5 & $(445.0)$ & 87 & 14.6 & $2.0^{\star \star *}$ & (1.3) & $240.4 † \dagger \dagger$ & (139.4) \\
\hline $\begin{array}{l}\text { Creams, ice creams } \\
\text { and desserts }\end{array}$ & 400 & 67.3 & 3.6 & (3.4) & 119.6 & $(100.1)$ & 137 & 23.1 & $2.1^{\star \star *}$ & (1.6) & $101.0 \dagger \dagger$ & $(72.6)$ \\
\hline Potatoes & 508 & 85.5 & 2.5 & (2.0) & 209.6 & (187.5) & 33 & 5.6 & $1.3^{\star \star}$ & $(0.8)$ & $175.8 \dagger$ & (83. \\
\hline Chips and processed potatoes & 472 & 79.5 & 4.1 & (3.3) & 147.3 & $(116.8)$ & 306 & 51.5 & $3.6^{*}$ & (2.5) & 130.3†† & (85.1) \\
\hline Vegetables & 532 & 89.6 & 1.2 & (1.8) & 129.3 & (122.1) & 51 & 8.6 & $0.2^{\star \star \star}$ & $(0.3)$ & 68.7††† & (54.6) \\
\hline Red meat and dishes & 520 & 87.5 & 4.4 & (3.3) & 138.7 & $(150.1)$ & 61 & 10.3 & $2.2^{\star \star \star}$ & (2.3) & $103.4 \dagger$ & $(109.4)$ \\
\hline Poultry and game (and dishes) & 427 & 71.9 & 2.3 & (1.9) & 125.4 & $(134.4)$ & 71 & 12.0 & $2.3^{\text {ns }}$ & $(1.6)$ & $147.0^{\text {ns }}$ & $(96.7)$ \\
\hline Meat products & 535 & 90.1 & 4.5 & (3.5) & 89.5 & $(78.3)$ & 269 & 45.3 & $3.1^{\star \star *}$ & (2.0) & $106.6+† \dagger$ & $(59.0)$ \\
\hline Sugars and confectionery & 578 & 97.3 & 7.3 & (5.2) & 55.2 & $(57.3)$ & 220 & 37.0 & $2.6^{\star \star \star}$ & (2.3) & $53.8^{\text {ns }}$ & (51.7) \\
\hline Savoury snacks & 485 & 81.6 & 4.1 & (3.1) & 41.3 & (31.5) & 148 & 24.9 & $1.8^{\star \star \star}$ & (1.2) & 33.7††† & (20.5) \\
\hline $\begin{array}{l}\text { Soups, sauces and } \\
\text { miscellaneous foods }\end{array}$ & 503 & 84.7 & 1.4 & (1.7) & 85.3 & $(119.6)$ & 164 & 27.6 & $0.6^{\star \star \star}$ & $(0.7)$ & $63.6+\dagger$ & (85. \\
\hline Beverages & 588 & 99.0 & 3.7 & (3.6) & 642.6 & $(572.4)$ & 368 & 62.0 & $1.5^{\star \star \star}$ & (1.5) & 388.6†† & (282.0) \\
\hline Other & 594 & 100.0 & 22.4 & $(8.2)$ & 421.1 & (425.4) & 169 & 28.5 & $1.4^{\star \star \star}$ & (1.4) & $135.5+t \dagger$ & (126.9) \\
\hline
\end{tabular}

SD - standard deviation.

The percentage energy from food was significantly different, at ${ }^{\star} P<0.05,{ }^{\star \star} P<0.00$ and ${ }^{\star \star \star} P<0.001$, between foods consumed at home and outside the home.

Food intake per eating occasion was significantly different, at $\uparrow P<0.05$, $\uparrow \uparrow P<0.01$ and $\dagger \dagger \dagger P<0.001$, between foods consumed at home and outside the home.

${ }^{\mathrm{ns}}$ Not significant $(P \geq 0.05)$.

The characteristics of each group were compared using Pearson's $\chi^{2}$. A higher proportion of non-consumers were found to be boys $(P<0.05)$ and younger children $(5-8$ years) $(P<0.05)$. Correspondingly, a higher proportion of high consumers were older children (9-12 years) $(P<0.05)$. In addition, a larger proportion of nonconsumers had parents with a lower education level, while a larger proportion of medium and high consumers had parents with higher education levels $(P<0.01)$. A number of other sociodemographic and health-related variables was also examined, but no associations were found. Intakes of a wide range of micronutrients were analysed but are not presented here (in general the same pattern was observed as for the nutrients presented).

Responses in a questionnaire on the frequency of consumption at various locations outside the home were analysed and compared with the actual frequency of consumption at those locations from the food diaries (Table 6). For the majority of locations, there was a tendency to underreport eating occasions in the questionnaire compared with the food diary. At least twice as many respondents consumed foods at a hotel/restaurant, fast food restaurant, public house/bar and cinema, and 1.5 times as many consumed foods from a local chip shop during the course of the survey (from the food diaries) as were reported in the questionnaire. The number of respondents who reported consuming foods in a coffee shop/deli and ethnic takeaway and those who actually did consume foods from these locations was comparable.

\section{Discussion}

Examination of the role of the food service sector in the diet is important for the development of practical FBDGs. In order for FBDGs to be effective, they need to be based on the prevailing patterns of the country for which they are being developed, and take into account the social and cultural elements of that society ${ }^{30}$. One aspect of the cultural context of the development of FBDGs extends to 'where' foods are consumed ${ }^{31}$. The NCFS is the most detailed investigation into food and nutrient intakes that has been carried out on children in Ireland. The fact that information on where the food was consumed was also collected creates the unique opportunity for the first examination of the role of the food service sector with regard to the diets of Irish children. Foods consumed outside the home have been shown to be of importance in the diets of children in other countries ${ }^{13-16}$, and these findings prompted the present study. Although $77 \%$ of Irish children consumed foods from outside the home, foods consumed at these locations accounted for just $6 \%$ of all eating occasions and only $9 \%$ of total energy intake in the sample population. There were few differences in food intakes at home compared with outside the home; 
Table 4 Number and percentage of consumers for food groups consumed at various locations outside the home, mean percentage contribution of food groups consumed outside the home to energy consumed outside the home, and mean food group intakes (g) per eating occasion outside the home for Irish children aged 5-12 years

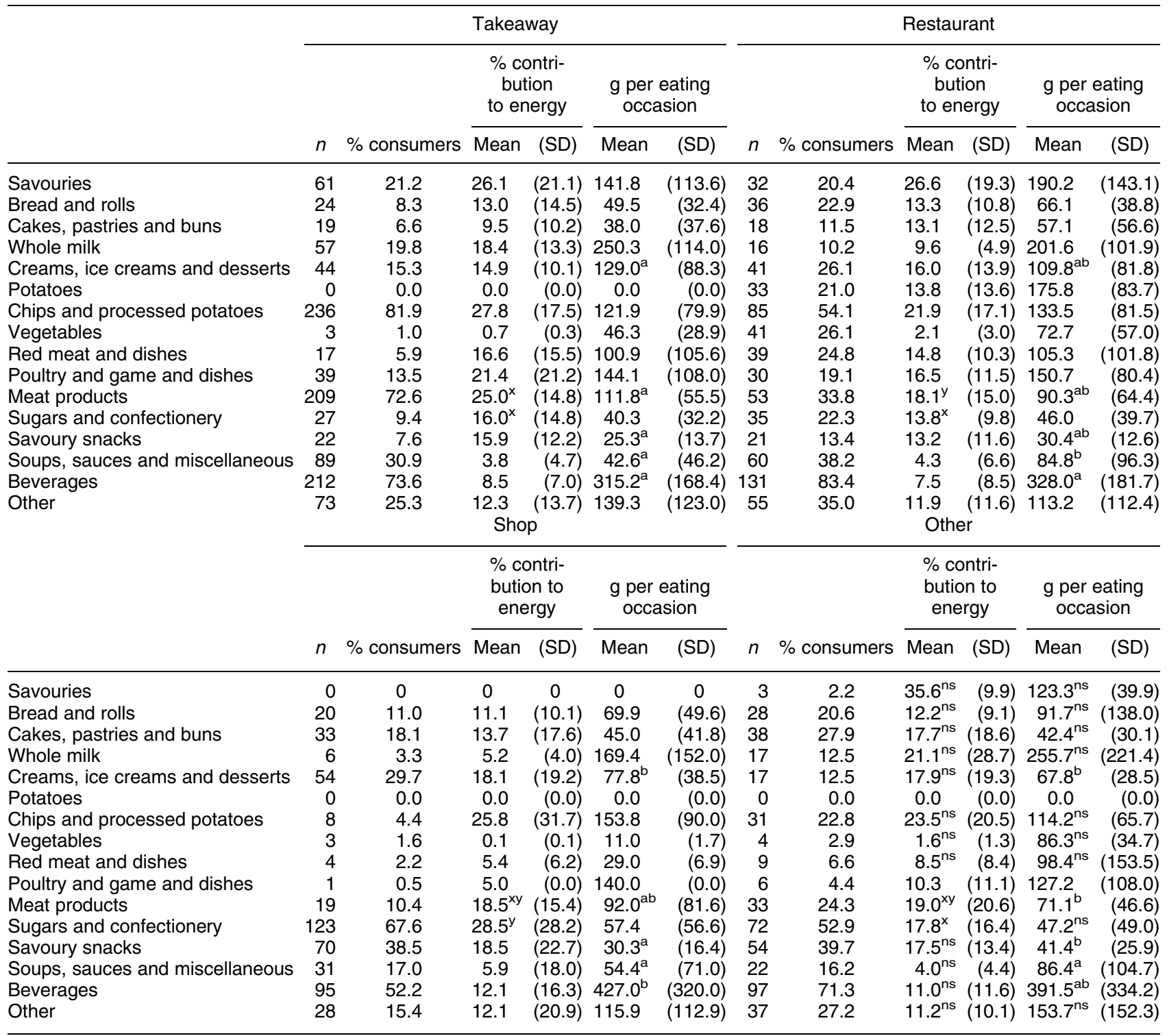

$\mathrm{SD}$ - standard deviation.

${ }_{x y}$ Different superscripts are significantly different $(P<0.05)$ between locations outside the home for \% contribution to energy.

${ }^{\mathrm{ab}}$ Different superscripts are significantly different $(P<0.05)$ between locations outside the home for g/eating occasion.

${ }^{\mathrm{ns}}$ Not significant $(P \geq 0.05)$.

however, nutrient intakes from foods consumed outside the home were less favourable than from foods consumed at home.

In the present study, $77 \%$ of children consumed food from outside the home on at least one occasion during the survey week. This is comparable with $71 \%$ of 8 - to 12 -yearold girls who consumed food away from home in a study conducted in the USA ${ }^{14}$. However, other studies examining fast food consumption in children and adolescents in the USA found that $30-42 \%$ were consumers on one or two survey days ${ }^{13,32}$, which is much higher than $48 \%$ of Irish children who were consumers at takeaways in general, on at least one eating occasion during the week (and 25\% from fast food establishments). This could be due to the older age group of these populations. Nicklas et al. (2004) found that 5.4\% of 10-year-old children from the Bogalusa study in the USA consumed foods at a sit-down or fast food restaurant on the day they were surveyed ${ }^{33}$. This appears to be similar to the number of consumers over the week in the present study. The present study found that children appear to consume more meals at home than found in other published surveys ${ }^{15,16,34}$, which is probably in part due to the fact that lunches are generally not provided at schools 
Table 5 Mean number of eating occasions per week outside the home and intakes of nutrients in groups of non-, low, medium and high consumers of foods outside the home (with tertiles based on the percentage of energy from foods eaten outside the home) for Irish children aged $5-12$ years

\begin{tabular}{|c|c|c|c|c|c|c|c|c|}
\hline & \multicolumn{2}{|c|}{$\begin{array}{l}\text { Non-consumers } \\
\quad(n=135)\end{array}$} & \multicolumn{2}{|c|}{$\begin{array}{l}\text { Low consumers } \\
\qquad(n=153)\end{array}$} & \multicolumn{2}{|c|}{$\begin{array}{l}\text { Medium consumers } \\
\qquad(n=153)\end{array}$} & \multicolumn{2}{|c|}{$\begin{array}{l}\text { High consumers } \\
\quad(n=153)\end{array}$} \\
\hline & Mean & (SD) & Mean & (SD) & Mean & (SD) & Mean & $(\mathrm{SD})$ \\
\hline $\begin{array}{l}\text { Eating occasions outside the home } \\
\text { per week }\end{array}$ & 0.0 & $(0.0)$ & $1.3^{x}$ & $(0.7)$ & $2.2^{y}$ & (1.3) & $4.1^{z}$ & (2.0) \\
\hline Energy in $\mathrm{MJ}$ & 7.1 & (1.6) & 7.0 & $(1.5)$ & 7.1 & (1.6) & $6.9^{\text {ns }}$ & (1.5) \\
\hline$\%$ energy from protein & 13.9 & (2.1) & 13.7 & (2.2) & 13.4 & $(2.2)$ & $13.4^{\mathrm{ns}}$ & (2.1) \\
\hline$\%$ energy from fat & $33.1^{\mathrm{a}}$ & $(4.5)$ & $33.5^{\mathrm{ab}}$ & (3.9) & $34.4^{\mathrm{ab}}$ & (4.4) & $34.7^{\mathrm{b}}$ & (4.0) \\
\hline$\%$ energy from carbohydrate & 52.6 & (5.0) & 52.3 & $(4.4)$ & 51.7 & (5.3) & $51.4^{\mathrm{ns}}$ & (4.5) \\
\hline$\%$ energy from sugar & 23.4 & $(4.8)$ & 24.2 & (5.0) & 24.3 & (6.1) & $23.6^{\text {ns }}$ & (5.1) \\
\hline Fibre (g) per $10 \mathrm{MJ}$ & $14.5^{\mathrm{a}}$ & (3.9) & $13.5^{\mathrm{ab}}$ & (3.6) & $13.2^{\mathrm{b}}$ & (3.4) & $12.6^{\mathrm{b}}$ & $(2.9)$ \\
\hline Calcium (mg) per $10 \mathrm{MJ}$ & $1304.6^{\mathrm{a}}$ & $(326.6)$ & $1312.7^{\mathrm{a}}$ & $(364.9)$ & $1235.0^{\mathrm{ab}}$ & (298.9) & $1144.3^{\mathrm{b}}$ & $(295.3)$ \\
\hline Iron (mg) per $10 \mathrm{MJ}$ & $14.8^{\mathrm{a}}$ & (5.4) & $13.9^{\mathrm{a}}$ & (3.9) & $12.7^{\mathrm{b}}$ & (3.3) & $12.7^{\mathrm{b}}$ & (3.4) \\
\hline Folate $(\mu \mathrm{g})$ per $10 \mathrm{MJ}$ & $358.5^{\mathrm{ab}}$ & (149.0) & $362.7^{\mathrm{a}}$ & $(142.4)$ & $318.4^{\mathrm{bc}}$ & $(108.8)$ & $295.1^{\mathrm{c}}$ & $(100.8)$ \\
\hline Vitamin C (mg) per $10 \mathrm{MJ}$ & $143.4^{\mathrm{a}}$ & $(126.0)$ & $142.7^{\mathrm{a}}$ & $(105.8)$ & $136.7^{\mathrm{ab}}$ & $(83.4)$ & $107.4^{\mathrm{b}}$ & $(68.0)$ \\
\hline
\end{tabular}

SD - standard deviation.

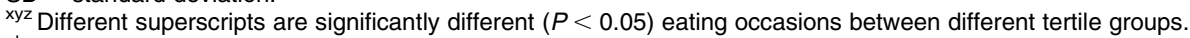

${ }^{\mathrm{abc}}$ Different superscripts are significantly different $(P<0.05)$ nutrient intakes between non-consumers and different tertile groups.

${ }^{\text {ns }}$ Not significant $(P \geq 0.05)$.

in Ireland. In the present study lunches consumed at school would have originated at home and would therefore have been coded as home. Eating occasions outside the home in Irish children accounted for just under $6 \%$ of the total number of eating occasions. The percentage of eating occasions at restaurants/fast food establishments in the present study was similar to that in American studies by Zoumas-Morse et al. (2001) ${ }^{15}$ and Lin et al. (1999) ${ }^{16}$. Magarey et al. (1987) reported much lower consumption at these locations in Australian children, but that study is almost 20 years old ${ }^{34}$. Lower consumption of foods away from home was also reported in 4- to 16-year-old Canadian children ${ }^{35}$, but these data were collected using a questionnaire, which from the findings of the present study would tend to indicate that consumption at locations outside the home may be underreported.

Foods consumed outside the home contributed to just $8.6 \%$ of the energy intake of children in Ireland in the whole sample and just $11 \%$ in those that consumed food outside the home (excluding those that did not eat outside the home). Energy intakes from foods consumed outside the home in the present study appear to be similar to those reported by Thompson et al. (2004) ${ }^{14}$. However, energy intakes from studies conducted by Bowman et al. (2004) ${ }^{13}$,
Zoumas-Morse et al. (2001) ${ }^{15}$ and Lin et al. (1999) $)^{16}$ are higher than those in the present study. This could be due to the fact that older children ( $2-19$ years) were included in those studies, different methodologies were used, i.e. mean intakes from 24-hour recall as opposed to mean daily intakes from a 7-day record, different definitions for eating occasions were used, cultural differences between populations, etc. Also, as in the present study, ZoumasMorse et al. (2001) $)^{15}$ and Lin et al. (1999) $)^{16}$ found higher fat (in terms of percentage of food energy) and lower micronutrient intakes from foods outside the home than at home. These findings for micronutrient intakes are not surprising given that a wider variety of food is usually consumed at home than outside the home, which would give rise to higher micronutrient intakes at home. The overall diet quality of high consumers of foods consumed from outside the home was slightly poorer than that of non- or low consumers for Irish children. This was similar to findings in other studies ${ }^{13,32,36}$.

As with all studies, there are difficulties in making comparisons due to methodological differences, some of which have been briefly mentioned. The definition of foods consumed outside the home is the first problem that arises when comparing published data. The majority

Table 6 Comparison of questionnaire-reported consumption at food service establishments and actual intake from the food diary in Irish children aged $5-12$ years

\begin{tabular}{|c|c|c|c|c|c|c|c|}
\hline & $\begin{array}{c}\text { Coffee } \\
\text { shop/deli }\end{array}$ & $\begin{array}{c}\text { Hotel/ } \\
\text { restaurant }\end{array}$ & $\begin{array}{l}\text { Local } \\
\text { chip shop }\end{array}$ & $\begin{array}{l}\text { Fast food } \\
\text { restaurant }\end{array}$ & Pub & Cinema & $\begin{array}{l}\text { Ethnic } \\
\text { takeaway }\end{array}$ \\
\hline \multicolumn{8}{|l|}{ Percentage who reported intake at each location } \\
\hline Less than once per fortnight/less frequently & 91.3 & 91.0 & 85.0 & 88.0 & 97.4 & 97.9 & 89.3 \\
\hline More than once per fortnight/more frequently & 8.7 & 9.0 & 15.0 & 12.0 & 2.6 & 2.1 & 10.7 \\
\hline \multicolumn{8}{|l|}{ Actual intake at each location } \\
\hline Percentage consumers at each location over the survey week & 7.7 & 22.1 & 23.2 & 24.7 & 5.9 & 5.7 & 11.1 \\
\hline
\end{tabular}


of studies base the definition on where the food was prepared or obtained, as in this study, but some base the definition on where the food was consumed, regardless of where it was prepared ${ }^{15}$. The location categories in the present study were chosen to suit the Irish population, as would be expected, but betweenstudy comparisons are quite difficult if different categories are used for each study. This is particularly true in the case of school as a location. Foods consumed at school by Irish children made a minute contribution to the Irish diet, as breakfasts or lunches are usually not provided in schools in Ireland. However, many of the peer-reviewed papers discussed herein are based in the USA where food is generally provided in schools. Another difficulty is that some studies are designed to examine the food service sector as a whole, whereas some studies just examine a particular element of it, for example fast food chains ${ }^{13,32}$. Other issues which make comparisons difficult are different data collection methods (e.g. 24-hour recall and 7-day record), various sample sizes and different age categories used in studies, etc. In terms of data analysis, another problem is that many published papers do not provide enough information on the calculation of mean intakes, e.g. are the intakes based on a mean of 7 days or the days on which the food was consumed at a given location, and does the mean represent the intakes for the total population or just the subpopulation who consumed food at a given location (i.e. consumers only). There is a limited amount of published literature which examines the contribution of foods consumed outside the home and particularly in children. The work on children is confined to the USA ${ }^{13-16}$, Canada ${ }^{35}$ and Australia ${ }^{34}$. Some other work includes children and adults together but does not present the results for subgroups of the population to examine the effects of foods away from home on the diets of children, adolescents and adults separately ${ }^{37}$.

One very interesting finding from this study is that the percentage of respondents who reported consuming foods from various locations outside the home from the questionnaires was much lower (twice as low in some cases) than actually occurred during the survey week. Aggregation of the questionnaire data erred on the lower side of intakes (more than once a fortnight rather than once or twice a week) so as not to be conservative. Researchers who assess food and nutrient intakes outside the home solely based on questionnaires should be aware that intakes might be underreported using this method. This information could also be used in the development of health promotion strategies in that people are not aware or do not acknowledge that they consume foods outside the home as often as they do. The investigation into food intakes at locations outside the home in the present study could also be useful in the establishment of FBDGs for children in Ireland. Foods such as chips, meat products, savouries, sugars and confectionery, and savoury snacks were of greatest importance at locations outside the home, with some being more prominent at certain locations. Guidelines to improve nutrient intakes at these locations could, for example, try to reduce the number of consumers and the amount of savoury snacks consumed at shops, or the amount of chips and meat products at takeaways and/or restaurants. These could serve as strategies to increase the number of children who achieve $<35 \%$ of their energy from fat. As a population, the children achieved the recommendations for fat and carbohydrate; however, $40 \%$ of the individuals did not achieve the target for fat $^{17}$. Also, health promotion messages to target foods consumed outside the home would not need to focus on any particular subgroups of the population, but rather on the population as a whole because, in general, differences were not found between sociodemographic groups. Food and nutrition policy could also aim to improve food choices available at locations outside the home. For example, healthier alternatives could be included on the menu or changes in the formulation of dishes, or cooking process could be encouraged to improve the nutritional quality of foods consumed outside the home.

This study will provide a basis for the development of FBDGs for Irish children both inside and outside the home.

\section{Acknowledgements}

This project was funded by the Department of Agriculture and Food (Ireland), through the Food Institutional Research Measure under the National Development Plan 2000-2006.

\section{References}

1 Euromonitor. The World Market for Consumer Foodservice, 2004 [online]. Available at www.euromonitor.com/gmid.def ault.asp

2 Central Statistics Office (CSO). Annual Services Inquiry 2002. Dublin: The Stationery Office, 2004.

3 Central Statistics Office (CSO). Household Budget Survey 1994/1995. Dublin: CSO, 1995.

4 Central Statistics Office (CSO). Household Budget Survey 1999/2000. Dublin: CSO, 2001.

5 Satia JA, Galanko JA, Siega-Riz AM. Eating at fast-food restaurants is associated with dietary intake, demographic, psychosocial and behavioural factors among African Americans in North Carolina. Public Health Nutrition 2004; 7: 1089-96.

6 Burns C, Jackson M, Gibbons C, Stoney RM. Foods prepared outside the home: association with selected nutrients and body mass index in adult Australians. Public Health Nutrition 2002; 5: 441-8.

7 French SA, Harnack L, Jeffery RW. Fast food restaurant use among women in the Pound of Prevention study: dietary, behavioral and demographic correlates. International Journal of Obesity 2000; 24: 1353-9. 
8 McCrory MA, Fuss PJ, Hays NP, Vinken AG, Greenberg AS, Roberts SB. Overeating in America: association between restaurant food consumption and body fatness in healthy adult men and women ages 19 to 80. Obesity Research 1999; 7: $564-71$.

9 Le Francois P, Calamassi-Tran G, Hebel P, Renault C, Lebreton S, Volatier JL. Food and nutrient intake outside the home of 629 French people of fifteen years and over. European Journal of Clinical Nutrition 1996; 50: $826-31$.

10 Loughridge JM, Walker AD, Sarsby H, Shepherd R. Foods eaten outside the home: nutrient contribution to total diet. Journal of Human Nutrition and Dietetics 1989; 2: 361-9.

11 Irish Universities Nutrition Alliance. North/South Ireland Food Consumption Survey Summary Report. Dublin: Food Safety Promotion Board, 2001.

12 O'Dwyer NA, Gibney MJ, Burke SJ, McCarthy SN. The influence of eating location on nutrient intakes in Irish adults: implications for developing food-based dietary guidelines. Public Health Nutrition 2005; 8: 258-65.

13 Bowman SA, Gortmaker SL, Ebbeling CB, Pereira MA, Ludwig DS. Effects of fast-food consumption on energy intake and diet quality among children in a national household survey. Pediatrics 2004; 113: 112-8.

14 Thompson OM, Ballew C, Resnicow K, Must A, Bandini LG, $\mathrm{Cyr} \mathrm{H}$, et al. Food purchased away from home as a predictor of change in BMI z-score among girls. International Journal of Obesity 2004; 28: 282-9.

15 Zoumas-Morse C, Rock CL, Sobo EJ, Neuhouser ML. Children's patterns of macronutrient intake and associations with restaurant and home eating. Journal of the American Dietetic Association 2001; 101: 923-5.

16 Lin BH, Guthrie J, Frazao E. Quality of children's diets at and away from home: 1994-96. Food Review 1999; 22: 2-10.

17 Irish Universities Nutrition Alliance. National Children's Food Survey, 2005 [online]. Available at www.iuna.net

18 Food Standards Agency. McCance and Widdowson's The Composition of Foods, 6th summary ed. Cambridge: Royal Society of Chemistry, 2002.

19 Holland B, Welch AA, Unwin ID, Buss DH, Paul AA Southgate DAT. McCance \& Widdowson's The Composition of Foods, 5th ed. London: HMSO, 1995.

20 Chan W, Brown J, Church SM, Buss DH. Meat Products and Dishes. Sixth Supplement to McCance \& Widdowson's The Composition of Foods, 5th ed. London: HMSO, 1996.

21 Chan W, Brown J, Lee SJ, Buss DH. Meat, Poultry and Game. Fifth Supplement to McCance \& Widdowson's The Composition of Foods, 5th ed. London: HMSO, 1995.

22 Chan W, Brown J, Buss DH. Miscellaneous Foods. Fourth Supplement to McCance \& Widdowson's The Composition of Foods, 5th ed. London: HMSO, 1994.
23 Holland B, Welch AA, Buss DH. Vegetable Dishes. Second Supplement to McCance \& Widdowson's The Composition of Foods, 5th ed. London: HMSO, 1996.

24 Holland B, Brown J, Buss DH. Fish and Fish Products. Third Supplement to McCance \& Widdowson's The Composition of Foods, 5th ed. London: HMSO, 1993.

25 Holland B, Unwin ID, Buss DH. Fruits and Nuts. First Supplement to McCance $\mathcal{E}$ Widdowson's The Composition of Foods, 5th ed. London: HMSO, 1992.

26 Holland B, Unwin ID, Buss DH. Vegetables, Herbs and Spices. Fifth Supplement to McCance \& Widdowson's The Composition of Foods, 4 ed. London: HMSO, 1991.

27 Holland B, Unwin ID, Buss DH. Milk Products and Eggs. Fourth Supplement to McCance \& Widdowson's The Composition of Foods, 4th ed. London: HMSO, 1989.

28 Holland B, Unwin ID, Buss DH. Cereal and Cereal Products. Third Supplement to McCance \& Widdowson's The Composition of Foods, 4th ed. London: HMSO, 1988.

29 Department of Health (UK). Dietary Reference Values for Food, Energy and Nutrients for the United Kingdom. Report of the Panel on Dietary Aspects of Food Policy. London: HMSO, 1991

30 Eurodiet Core Report. Nutrition and diet for healthy lifestyles in Europe: science and policy implications. Public Health Nutrition 2001; 4: 265-73.

31 Kearney JM, Hulshof KF, Gibney MJ. Eating patterns temporal distribution, converging and diverging foods, meals eaten inside and outside of the home - implications for developing FBDG. Public Health Nutrition 2001; 4: 693-8.

32 Paeratakul S, Ferdinand DP, Champagne CM, Ryan DH, Bray GA. Fast-food consumption among US adults and children: dietary and nutrient intake profile. Journal of the American Dietetic Association 2003; 103: 1332-8.

33 Nicklas TA, Morales M, Linares A, Yang SJ, Baranowski T, De Moor C, Berenson G. Children's meal patterns have changed over a 21-year period: the Bogalusa heart study. Journal of the American Dietetic Association 2004; 104: 753-61.

34 Magarey A, Nichols J, Boulton J. Food intake at age 8. 2. Frequency, company and place of meals. Australian Paediatric Journal 1987; 23: 179-80.

35 Gillis LJ, Bar-Or O. Food away from home, sugar-sweetened drink consumption and juvenile obesity. Journal of the American College of Nutrition 2003; 22: 539-45.

36 Gonzales EN, Marshall JA, Heimendinger J, Crane LA, Neal WA. Home and eating environments are associated with saturated fat intake in children in rural West Virginia. Journal of the American Dietetic Association 2002; 102: 657-63.

37 Department for Environment, Food and Rural Affairs. Family Food in 2002-03. London: The Stationery Office, 2004. 